\title{
Effective factors on menstrual health among female students in Bam city: a qualitative study
}

Mohammad Ali Morowatisharifabad ${ }^{1}$, Aliakbar Vaezi ${ }^{2}$, Neda Mohammadinia ${ }^{3}$

${ }^{1} \mathrm{PhD}$ of Health Education, Professor, Ageing Health Department, School of Public Health, Shahid Sadoughi University of Medical Sciences, Yazd, Iran

${ }^{2} \mathrm{PhD}$ of Nursing, Assistant Professor, Nursing Department, School of Nursing \& Midwifery, Shahid Sadoughi University of Medical Sciences, Yazd, Iran

${ }^{3} \mathrm{PhD}$ Student in Health Education and Health Promotion, International Campus, Shahid Sadoughi University of Medical Sciences, Yazd, Iran

\section{Type of article: Original}

\begin{abstract}
Background: Menarche is an independent puberty event in a girl's life, and is associated with physical growth, ability in marriage and fertility. Therefore, poor menstrual health can be a major determinant of morbidity, as well as physical, mental and social problems in this age group.

Objective: The aim of this study was to explore the effective factors on menstrual health among female students in Bam city.

Methods: The qualitative study was conducted using content analysis approach in 2017. The participants were 32 individuals consisting of 13 students, 10 mothers of the same students, 9 school associates and health educators of 5 secondary schools in Bam city, who were selected based on an objective-oriented approach. The sampling was done until data saturation. Data collection methods were semi-structured and in-depth interview. Data analysis was performed using the steps suggested by Graneheim and Landman.

Results: There were two categories (easy interaction and inappropriate adaptation to changes in health behavior), 13 sub-categories and 52 initial codes. The positive factors included easy access to sanitary pads, appropriate school education, easy access to health and therapeutic services and school flexibility on menstrual issues, while the negative factors included inadequate facilities for sanitary pad disposal, lack of access to informed people about menstrual issues, insufficient attention to menstrual problems, feeling ashamed, the high cost of menstrual health, self-medication with traditional medicines, inadequate self-directed education, lack of awareness and trust in health center staff, and following family and teachers in menstrual problems.

Conclusion: Overall, this study indicated that economic, social, cultural and educational factors affect menstrual health. Therefore, the identification of each of these factors helps planners to apply the most appropriate methods and strategies for menstrual health improvement.
\end{abstract}

Keywords: Menstrual hygiene, Health behavior, Menstruation, Qualitative study, Iran

\section{Introduction}

Menarche is the most important sign of puberty (1) and in Iran, the average age of most girls when it occurs, is 12.81 years (2). Menarche has been described as an independent puberty event in a girl's life and is accompanied by physical growth, ability in marriage and fertility (3). Several studies have shown that the majority of teenage girls have inappropriate and incomplete knowledge about the health and physiology of menstruation (4). A study conducted on Egyptian teenage girls indicated that their level of knowledge, beliefs and health performance related to menstruation was low (5). Also, in a study in Baghdad, the knowledge of teenage girls about menstruation was weak and this limited their health practice according to their beliefs (6). There are few and inappropriate available

\section{Corresponding author:}

Neda Mohammadinia, International Campus, Shahid Sadoughi University of Medical Sciences, Yazd, Iran.

Tel: +98.3434225080, Email: nedamohammadinia@yahoo.com

Received: October 04, 2017, Accepted: December 28, 2017, Published: February 2018

iThenticate screening: December 28, 2017, English editing: January 10, 2018, Quality control: January 15, 2018

This article has been reviewed / commented by five experts

(C) 2018 The Authors. This is an open access article under the terms of the Creative Commons Attribution-NonCommercialNoDerivs License, which permits use and distribution in any medium, provided the original work is properly cited, the use is non-commercial and no modifications or adaptations are made. 
educational resources about reproductive health in adolescents. Therefore, in studies conducted in Iran and other countries, the most important information resources of girls in this field were mothers (7-10), teachers (10), and friends and relatives (8). Unfortunately, their weak knowledge in this field and adherence to a series of traditional customs worsens the problem. Although menstruation health education and increase in knowledge about menstruation in teenagers can decrease complications such as morbidity, in addition to physical, mental and social problems related to poor menstrual health (7); inappropriate and insufficient health education in girls' schools, results in the making of incorrect decisions about their personal health and menstruation management (8). Embarrassment, avoiding participation in genital health discussion (11), believing in menstruation privacy, as well as the superstitious beliefs surrounding it make its discussion and education of girls, difficult (8). Health personnel, due to lack of time, lack of educational equipment, shortage of training personnel, inappropriate coordination between health centers and schools and the sensitivity of the subject to general education, cannot effectively conduct training, since they lack an organized schedule in schools (11). A study conducted in the USA, showed that only $2 \%$ of teenagers received their information from health personnel (7). Therefore, available resources, accessibility, places of reference, educational sessions and types of services affect health practice, and can improve health behaviors or prevent them (12). Three main groups of menstrual health enhancements are mass media and their message about puberty, menstruation and related points, and female-centered education through curriculum lessons or out-of-school programs, providing relevant books and building capacity in society by educating teachers and parents (13). However, the menstrual health education program is wider, but is affected by the school environment and infrastructure such as access to essential menstrual health supplies, restrooms, pad replacement locations, water and sanitation facilities, as well as the proper sanitary functions such as washing hands with soap (4). Attention to the mentioned items revealed that the phenomenon of menstrual health is complicated and affected by different physiological, cultural, social, economic and other factors. Some of these factors are unknown. Despite quantitative research and several studies conducted in Iran and other countries (7-10), some dimensions are still relatively unknown. In other words, people in different societies confront it with different methods. In America, most people use NSAID and OCP drugs to treat dysmenorrhea (7) but in Bangladesh, most girls remain at home during menstruation (8). A study in five African countries indicated that on average, $49 \%$ of interviewed girls missed four days per month due to menstruation (14). It is possible that this confrontation occurred with defective knowledge or due to lack of access and facilities especially in schools, and results in inappropriate menstrual management consequences. Therefore, to understand this and to have several years of health education experience in schools and address the topics raised by students, researchers have decided to identify and explain available infrastructure and facilities (effective factors on menstrual health), with qualitative research, using in-depth interviews in students' own language. Therefore, the goal of this study was to explore effective factors on menstrual health among female students.

\section{Material and Methods}

\subsection{Research design and participants}

This is a qualitative study with Directed Content Analysis. The participants were 32 individuals (13 students and 10 mothers of the same students, 9 school associates and health educators) of 5 secondary schools in Bam city (2 private schools and 3 public schools). Inclusion criteria were filling the consent form, active participation in interviews and having experienced at least three menstruation cycles. Participants were selected based on an objective-oriented approach and continued until data saturation (not extract new code).

\subsection{Interviews and data collection}

The method of data collection was in-depth and semi-structured interviews. The Average duration of interview was 40 minutes. The interviews were based guidance questions on the effective factors in Menstrual Health (access to educational, environmental health, economical facilities). The interviews began with this question: "In your experience, what is your perception of menstruation?" Wherever necessary, further elicitation was used such as give some examples, or explain more and do you have a specific suggestion or viewpoint? The interviews were conducted from November 2016 to April 2017. The locations of the interviews were the conference room or prayer room of schools. The time of interview was based on students' weekly schedule in coordination with the director and associate principal of schools. Each interview was analyzed using the steps suggested by Graneheim and Landman (15). The unit of analysis consisted of all interviews. Therefore, the following steps were taken respectively: writing the interview word by word immediately after each interview, reading the text several times to generally comprehend it, dividing the text into units of meaning, summarizing the units of meaning and coding, classification of initial codes into sub-categories and categories based on comparison of their similarities and differences, and finally, extracting themes as expressions of hidden content in data. The data achieved from each 
interview were guidance for the next interview. In this way, sampling continued until data saturation. Data analysis began after the first interview and continued with data collection.

\subsection{Accuracy and stability of data}

Accuracy and stability of data was assessed by the Lincoln and Guba method (16) to ensure the accuracy credibility, self-monitoring for comparison of researcher's interpretation with the participant's intention. So, the next day, the interview text and extracted codes were given to participants, who discussed the accuracy of the researcher's interpretation. In cases of contradiction, the issues were reconsidered. In order to confirm dependency, the experts' panel and external check methods were used. For assessment of transferability, maximum variety of participants with respect to age, school type, years of menstruation experience were considered.

\subsection{Ethical Considerations}

First, the study was approved by the ethics committee of Yazd University of Medical Sciences (ethical approval code: IR.SSU.SPH.REC.1395.148). Second, before the interview, the researcher introduced herself, described research objectives for participants and obtained oral and informed consent from them. In this way, the researcher took precise conversation notes and wrote all non-verbal movements. The participants were assured about the confidentiality of their information and their voice record. The participants were free to leave the study at any stage.

\section{Results}

In total, 32 individuals participated in the study (p1-13 students, p14-23 mothers and p24-32 teachers). The average age was $14.8 \pm 0.34$ for students, $38.2 \pm 2.2$ for teachers and $41 \pm 3.40$ for mothers. The average duration of interview was 40 minutes. The majority of mothers (70\%) were housewives with the education level of high school and higher (75\%). The majority of teachers had a bachelor's degree (92\%). The analysis also identified 52 initial codes, 13 sub-categories and two categories from factors concerning behavior change of menstrual health (Tables 1,2$)$.

Table 1. Examples of codes delivered from units meaning

\begin{tabular}{|l|l|l|}
\hline Code & Condensed unit meaning & Unit meaning \\
\hline $\begin{array}{l}\text { Easy access to } \\
\text { sanitary pads }\end{array}$ & $\begin{array}{l}\text { Easy preparation of sanitary pads at } \\
\text { home }\end{array}$ & $\begin{array}{l}\text { "Their father buys their sanitary napkin box. We have } \\
\text { two adult girls who have no problem in this case" }\end{array}$ \\
\hline $\begin{array}{l}\text { Proper school } \\
\text { education on } \\
\text { menstruation }\end{array}$ & $\begin{array}{l}\text { Invitation of informed person for } \\
\text { menstruation problems }\end{array}$ & $\begin{array}{l}\text { "We invited a midwife to talk about menstruation } \\
\text { problems for students in health week, the previous } \\
\text { year. They asked her their questions" }\end{array}$ \\
\hline $\begin{array}{l}\text { Self-medication } \\
\text { with traditional } \\
\text { medicines }\end{array}$ & $\begin{array}{l}\text { Self-medication recommended by } \\
\text { family, self-medication recommended } \\
\text { by friends }\end{array}$ & $\begin{array}{l}\text { "I instinctively contact my aunt if any problem arises, } \\
\text { and she immediately prescribes herbal medicine" }\end{array}$ \\
\hline
\end{tabular}

Table 2. Codes, sub-categories and categories of effective factors among female students

\begin{tabular}{|c|c|c|}
\hline Category & Sub category & Code \\
\hline \multirow[t]{4}{*}{ Easy interaction } & $\begin{array}{l}\text { Easy access to sanitary } \\
\text { pads }\end{array}$ & $\begin{array}{l}\text { Easy access to sanitary pads at home, easy access to free sanitary pads } \\
\text { at school, easy access to sanitary pads in school shop }\end{array}$ \\
\hline & $\begin{array}{l}\text { Proper school } \\
\text { education on } \\
\text { menstruation }\end{array}$ & $\begin{array}{l}\text { Several training sessions by midwife about menstruation, inviting a } \\
\text { consultant or informed person to teach menstruation issues at school, } \\
\text { access to a school consultant about menstruation problems }\end{array}$ \\
\hline & $\begin{array}{l}\text { Easy access to health } \\
\text { and therapy }\end{array}$ & $\begin{array}{l}\text { School near to health center or treatment center, referral to physician } \\
\text { with their mothers in times of emergency, referral to physician with } \\
\text { older sister in times of emergency }\end{array}$ \\
\hline & Schools' flexibility & $\begin{array}{l}\text { The school deputies immediately contact students' parents in } \\
\text { menstruation problems, lets students leave school in menstruation } \\
\text { problems, good communication between school and student's family }\end{array}$ \\
\hline \multirow[t]{2}{*}{$\begin{array}{l}\text { Inappropriate } \\
\text { Adaptation }\end{array}$} & $\begin{array}{l}\text { Inadequate facilities } \\
\text { for sanitary pad } \\
\text { disposal }\end{array}$ & $\begin{array}{l}\text { Difficulty in disposing of sanitary pads because of limited number of } \\
\text { trash bins, difficulty in disposing of sanitary pads because of lack of } \\
\text { privacy environment at school, difficulty in disposing of sanitary pads } \\
\text { because of father's or brother's presence at home }\end{array}$ \\
\hline & $\begin{array}{l}\text { Lack of access to } \\
\text { informed people about }\end{array}$ & $\begin{array}{l}\text { Lack of access to informed individuals on menstrual issues at school, } \\
\text { access to health instructors only one day a week, no access to physician }\end{array}$ \\
\hline
\end{tabular}




\begin{tabular}{|l|l|l|}
\hline menstrual issues & or midwife at school. \\
\cline { 1 - 3 } & $\begin{array}{l}\text { Feeling of embarrassment talking to the health instructor about } \\
\text { menstruation problems. }\end{array}$ \\
\hline $\begin{array}{l}\text { Insufficient attention } \\
\text { to menstrual problems }\end{array}$ & $\begin{array}{l}\text { Not consideration to some unusual menstrual problems at home, not } \\
\text { following unusual menstrual problems }\end{array}$ \\
\hline $\begin{array}{l}\text { The high cost of } \\
\text { menstrual health }\end{array}$ & $\begin{array}{l}\text { The high cost of treatment and follow-up of menstrual problems, the } \\
\text { high cost of appointment with doctor }\end{array}$ \\
\hline $\begin{array}{l}\text { Self-medication with } \\
\text { traditional medicines }\end{array}$ & $\begin{array}{l}\text { Self-medication recommended by others, availability to self-medication } \\
\text { drugs, self-medication instead of referring to a doctor }\end{array}$ \\
$\begin{array}{l}\text { Inadequate self- } \\
\text { directed education }\end{array}$ & $\begin{array}{l}\text { Unavailability to educational programs, CDs or books about } \\
\text { menstruation, lack of media programs about menstruation }\end{array}$ \\
\hline $\begin{array}{l}\text { Lack of awareness and } \\
\text { trust in health center } \\
\text { staff }\end{array}$ & $\begin{array}{l}\text { Insufficient trust in midwife for treatment of menstruation problems, no } \\
\text { trust in health centers for follow-up of menstruation problems, no } \\
\text { awareness about midwife's presence at health centers }\end{array}$ \\
$\begin{array}{l}\text { Following family and } \\
\text { teachers in menstrual } \\
\text { problems }\end{array}$ & $\begin{array}{l}\text { Compliance of parents about menstrual problems, compliance of family } \\
\text { expert about menstrual problems, talk to their mothers and } \\
\text { grandmothers about menstruation problems }\end{array}$ \\
\hline
\end{tabular}

\subsection{Easy interaction}

Easy interaction was the first category obtained in this study. It shows features and skills that facilitate change in the behavior of menstrual health. Easy interaction in this study, consists of five sub-categories (easy access to sanitary pads, appropriate school education, easy access to health and therapeutic services and school flexibility on menstrual issues).

\subsubsection{Easy access to sanitary pads}

Easy access to sanitary pads have an important role in girls' menstrual health that most of the participants mentioned easy access to sanitary pads at home and school (if urgently needed, free at schools). One of the eighth-grade students said, regarding easy access to sanitary pads at school: "We have no problem at school. I was in menstruation period the previous week and got a sanitary pad from the health educator. There are free sanitary pads for everyone who menstruates at school. We have no problem" (p5). One of the mothers laughed, while she spoke about access to sanitary pad at home: "Their father buys the sanitary pad box. We have two adult girls who have no problem in this case" (p20).

\subsubsection{Proper school education on menstruation}

Education and informing students regarding menstruation at school is essential. They should know about their menstruation. Some teachers from different schools mentioned several training sessions about menstruation and inviting a consultant or informed person to teach menstruation issues at school. Some students mentioned they had access to a school consultant in case of menstruation problems. A middle-aged health educator of one of the schools said about it: "We invited a midwife to talk about menstruation problems for students during health week, the previous year. They asked her their questions" (p25). Another teacher who had been associate principal for 10 years, said: "Usually, at the beginning of every educational year, we have training sessions about health problems, nutrition and menstruation" (p28). One contented seventh-grade student said: "For any problem about menstruation, we refer to the health educator or school consultant and get guidance" (p3).

\subsubsection{Easy access to health and therapeutic services}

Easy access, in this article refers to geographic availability and opportunity to use health and therapeutic care. Most participants stated that their school and home are near to health and therapeutic centers because their city is not too big. One of the ninth-grade students said about it: "There is one health center near the school and a specialist clinic near to our home. Last week, I complained about not having menstruation for 3 to 4 months so my mother took me to the specialist without any problem "(p8). One 40-year-old mother, on the subject of access to health and therapeutic centers laughed and said: "Bam is a small city. We have easy access to a doctor, as the health center is near the school and the hospital is on the next street. Thank God, we have no problem about it" (p17).

3.1.4. Schools' flexibility

Schools' flexibility refers to the absence of severity concerning menstruation problems in the schools studied. Participants said that usually, the school deputies contact parents and let students leave school. Most participants stated there is good connection between school and home. One of the students while rubbing her stomach, said: "Whenever I menstruate, I have stomach ache, so immediately get permission and go home" (p4). Another student 
from another school said: "There is no severity of teachers even if our mothers phone the school, our absence is justified" (p2).

\subsection{Inappropriate adaptation}

Inappropriate adaptation points to factors and barriers that prevent change of behavior in menstrual health. It includes nine sub-categories: Inadequate facilities for sanitary pad disposal, lack of access to informed people about menstrual issues, insufficient attention to menstrual problems, feeling ashamed, the high cost of menstrual health, self-medication with traditional medicines, inadequate self-directed education, lack of awareness and trust in health centers staff, and following family and teachers in menstrual problems.

\subsubsection{Inadequate facilities for sanitary pad disposal}

Inadequate facilities for disposal of sanitary pads include the limited number of toilets and trash bins, the lack of privacy and comfortable environment at school, or problems in disposing sanitary pads because of presence of the father or brother at home. One of the ninth-grade students who protested about disposing sanitary pads said: "When I menstruate during school days, I am worried about going to the restroom because there are three small toilets with only two trash bins. So, we cannot dispose of sanitary pads easily. We try to be careful that nobody will see us. I am embarrassed" (p6). Another student, embarrassed about this problem said: "At home, my father disposes of the garbage. So, when I am in menstruation period I am embarrassed that he understand" (p7).

3.2.2. Lack of access to informed people about menstrual issues

Access to informed people regarding menstrual issues helps students to answer the questions and problems about menstruation and to have ideas or viewpoints about menstruation issues. In this study, in some schools, especially public schools, the majority of mothers and students complained about this subject; for example, access to a health instructor only one day a week at some schools and no access to a physician or midwife at school or even a consultant or speaker. One of the mothers commenting about the need for these people said with discomfort: "I wish there was a midwife or physician at least one hour every week or every month at school, so that students could ask their questions, especially at this age" (p22). One of the students commented: "The health instructor is at school only one hour every week. If there are any questions, other teachers refer us to the health instructor" (p13). One of the ninth-grade students also confirmed this and stated: "During this term, there was no person to explain menstruation, normal symptoms, what to eat and what not to eat. The school principal could invite an informed speaker or consultant" (p1).

\subsubsection{Insufficient attention to menstrual problems}

Insufficient attention is normal, considering some unusual menstrual problems. One of the seventh-grade students talked about this insufficient attention indifferently saying: "I always have stomach and back ache before my menstruation period. Sometimes I have pain at both sides of my body. But, my grandmother always says it is normal and not a problem" (p2). One of the eighth-grade students who was overweight laughed and said: "Last year, I had my menstruation period only once in two or three months, but my mother said it is normal. Till now, my menstruation is irregular. Some people say it is due to being overweight, but my mother says there is no problem" (p7).

\subsubsection{Feeling ashamed}

Feeling ashamed has cultural roots and there is a culture of silence about menstrual issues in many developing countries. Some students mentioned their shame on talking to a health instructor about menstruation problems. One of the seventh-grade students who had one-year menstruation experience, in this subject said: "It is so hard to talk about menstruation problems (shameful). Now you are asking about menstruation, I am not comfortable in answering"(p2).

3.2.5. The high cost of menstrual health:

Some of the participants, especially mothers, mentioned the high cost of treatment and doctor's visits as a barrier to pursue menstruation problems. One of the mothers who was 45 years old and a housewife said about the high cost of a doctor's visit: "If my daughter has a small pain, I won't take her to the doctor because, although we are insured; costs of a visit, laboratory and sonography which are routine, are now about 2,000,000 I.R. Rial" (p14).

\subsubsection{Self-medication with traditional medicines}

Self-medication is one of the most common health problems also referred in this study. One of the students smiled and said about self-medication: "I have had menstruation periods for three years. In case of any discomfort, my mother gives me herbal tea and persists on its effectiveness" (p6). One of the old teachers who was the school education deputy said about self-medication: "We always have herbal medicines at home. It is a part of our culture and tradition and we believe in them so much" (p30). 


\subsubsection{Inadequate self-directed education:}

Self-directed education about menstruation includes CD, books, booklets, media programs or pamphlets about it. Some of the participants mentioned no access to these resources. One of the mothers whose oldest child was in seventh-grade said: "It would be so good if they could give students educational CDs or books about menstruation. Our knowledge is not sufficient. Children should have practical and up-to-date knowledge" (p21).

3.2.8. Lack of awareness and trust in health center staff:

Some of the participants do not know health center staff and some of them that do know, do not have sufficient trust in them. A student unaware of the presence of a midwife in health centers and does not have sufficient trust in the center physician said: "There is one health center behind the school, but even when I have severe pain, I do not go to doctor there and instead, go to a specialist with my mother. But regarding the midwife, I did not know whether there was a midwife in the health center or not. I thought only young children went there for vaccination and weight control" (p11).

\subsubsection{Following family and teachers in menstrual problems}

Most of the participants stated that they followed family and teachers in menstrual problems instead of referring to a midwife or physician. They mentioned that in menstruation problems, the majority of students talk to their mothers and grandmothers. The children trusted their parents, teachers and experienced family members. One of the ninthgrade students talking about using her mother's experience said: "If I have any problem, for example hemorrhage, severe dysmenorrhea, amenorrhea, I talk to my mother and she asks other relatives especially my grandmother, and based on their experience they treat me. I follow my mother and I seldom refer to a physician" (p9).

\section{Discussion}

The analyzed data of this study, led to the classification of effective factors on menstrual health in two categories: Easy interaction and Inappropriate Adaptation. In this study, easy interaction facilitates change of health behavior including: easy access to sanitary pads, proper school education on menstruation, school flexibility, easy access to health and therapeutic services. The majority of participants in this study pointed to these aspects as positive factors on health behavior. In the studied population, the relative appropriate price of sanitary pads and the different types in pharmacies and markets lead to its easy access although some studies indicated that women and girls had problems with the provision of sanitary pads (17). In a study in Bangladesh, only $24 \%$ of girls were able to use sanitary pads even after educational intervention (8). Therefore, access to sanitary pads is affected by place of residence, individuals' social and economical conditions and the price of sanitary pads. In this study, participants especially in private schools, pointed to proper education on menstruation. Since the studied population is from urban schools and they had a health instructor at least one day a week, it is acceptable to hold educational sessions during the year regarding important subjects such as menstruation. A similar study in north Ethiopia indicated that only $25 \%$ of school girls were educated about menstruation and menstrual health management at school. But girls' knowledge and access to menstrual health education was almost dependent on their place of residence. In Ethiopia, girls who live in Addis Ababa or nearby districts, reported more access to educational sessions. In Addis Ababa, 90\% of girls were educated about menstruation (18). In a study in Indonesia, 50\% of schools had menstruation education at least once a year (11). In the case of setting up more education sessions in private schools, it can be related to the employment status of health educators in different schools. In private schools, they are contractually obligated, so try to stabilize their future presence with better performance but in public schools, health care providers are formally hired to work at two or three schools. In this study, the participants were satisfied with local health centers. The reasons were the small size of the city and the existence of one health center in each district. This is due to the type of service delivery system (network system) in Iran and efforts to achieve basic health care which is the easy access to services. Regarding flexibility of schools on menstruation; all participants admitted that schools cooperate with students during menstruation and even let them leave school due to sensitivity of teachers to menstruation and importance to girls and their conditions. Although, in reviewed studies there was nothing found about allowed or unauthorized absence from school. But the repetition of students' absences per month is even mentioned in UNICEF reports $(19,20)$. Inappropriate adaptation points to factors and barriers that prevent change in menstrual health behavior. It includes: inadequate facilities for sanitary pad disposal, lack of access to informed people about menstrual issues, insufficient attention to menstrual problems, feeling ashamed, the high cost of menstrual health, self-medication with traditional medicines, inadequate self-directed education, lack of awareness and trust in health center staff, and following family and teachers in menstrual problems. Lack of privacy and lack of facilities for sanitary pad disposal in other studies conducted in Kenya, Indonesia, Ethiopia and Rwanda, pointed out that school restrooms had weak menstruation health indices such as facilities to dispose of sanitary pads $(11,18,21-23)$. It is obvious that these indices related to social, economical and cultural conditions of the studied environment. In this study, lack of privacy to change sanitary pads is related to the small size of school restrooms and the large number 
of students which are resulted from society, economic issues and low number of schools in proportion to population. Participants declared no access to informed people about menstruation issues especially in public schools. Although, there were educational sessions at some schools, in special times (health day) and by a consultant or health instructor. Some students and parents complained about lack of a resident health instructor at school and lack of expert people in menstruation problems (midwife, physician) and education sessions. Although the place and type of school had an influence on educational programs, several studies also confirmed lack of menstruation educational programs in schools (24-26) and preferred health staff as a source of information for education in schools (11). But schools' financial status to invite a counselor, doctor, or midwife, health staff's lack of time, lack of educational tools, inappropriate coordination between schools and health centers, the sensitivity of the issue and its being taboo may be the reasons for this lack of programs. Of course, inadequate self-directed education such as CDs, booklets, pamphlets, posters in schools and media programs was another sub category, while media, especially TV health programs, may have a significant role in improving the knowledge related to health (27). Other preferred sources for girls' education are: Internet, workshops, books and other written sources which can be used (11). Feeling ashamed was the subcategory which has cultural roots. In many developing countries, there is the culture of silence about menstrual issues (8) that increases shame, misunderstanding and negative attitude $(11,20)$. In a similar study, due to embarrassment, $19 \%$ of student girls did not attend menstrual education class (13), even though menstrual education breaks down this defective cycle and helps to conducted health behavior during menstruation. Self-medication, insufficient attention to menstrual problems and following family and teachers in menstrual problems, were delivered sub-categories that circular is interconnected. Regarding insufficient attention to menstrual problems in this study, most of it was due to the incorrect attitude that menstruation is a physical and physiological problem so most of its complaints are not serious and are normal. As a result, it is not deemed necessary to visit a physician or follow up. In these cases, the availability of herbal medicines, other people's recommendations, and following family and teachers in menstrual problems, increase self-medication of these drugs. In some studies, the most important reasons for self-medication were, lack of necessity (28) to refer to a physician, unimportance and inattentiveness to the problem (29). On the other hand, the high cost of menstruation health and treatment of problems, especially a physician's visit and follow-up tests declared by participants, increase self-medication especially by using herbal medicines. The results of the studies conducted in Kerman, Esfahan and Ahvaz indicated a consistency with the present study $(28,29)$. In Iran, the cost of visiting a physician and the price of laboratory diagnostic and radiology services is high, especially if the individual is not insured. Most mothers and their girls had lack of awareness and trust in health center staff that the causes may be the inadequate public notification regarding low cost, personnel and services of health centers. Regarding the study limitations, the limitation of the present study was embarrassment to explain menstruation issues and not having full honesty in expressing self-medication, especially in teachers and mothers' groups.

\section{Conclusions}

The findings of the present study indicated that different factors have an effect on girls' menstrual health. Thus, identification of each of these factors helps planners to apply the most appropriate methods for menstrual health improvement. Therefore, it is suggested to hold educational classes by expert people for teachers, mothers and students about girl's issues and proper care, to prepare self-directed education materials, focus more on supervision to the health of the school environment and restrooms. Finally, it is suggested that other qualitative researches explore menstruation beliefs in the cultural context.

\section{Acknowledgments:}

This paper was a part of the Ph.D. dissertation project that was funded by Shahid Sadoughi University of Medical Sciences (1395.148). We thank students, their mothers and secondary school personnel who helped us collect the data for this study.

\section{Conflict of Interest:}

There is no conflict of interest to be declared.

\section{Authors' contributions:}

All authors contributed to this project and article equally. All authors read and approved the final manuscript.

\section{References:}

1) Khalili poor M. Principles and treatment of women diseases, labor and gravidity. 2th ed. Tehran: Khosravi; 2012. 
2) Bahrami N, Yiong H, Ghojanzadeh M, Mirmiran P. Menarche age in Iran: A meta-analysis. Iran J Nurs Midwifery Res. 2014; 19(5): 440-50.

3) Ostovar R, Fararuie M, Mohamed F. Comparison of Classic vs. Role plays Teaching Methods on the Menstrual Hygiene Behavior of Secondary School Girls in Iran. Armaghane-danesh. 2013; 18(5): 92.

4) Adika, V, Ayinde M, Jack-Ide I. Self-care practices of menstrual hygiene among adolescents school going girls in Amassoma Community, Bayelsa State. International Journal of Nursing and Midwifery. 2013; 5(5): 99-105. doi: 10.5897/IJNM2013.0102.

5) Adinma E, Adinma J. Perceptions and practices on menstruation amongst Nigeria secondary school girls. African journal of reproductive health. 2008; 12(1): 74-83. PMID: 20695158.

6) Sadiq MA, Salih AA. Knowledge and Practice of Adolescent Females about Menstruation in Baghdad. Journal of General Practice. 2013; 2(138). doi: 10.4172/2329-9126.1000138.

7) Avril M, Houston A, Zehihuan H, Lawerence J. Knowledge, Attitudes, and Consequences of Menstrual Health in Urban Adolescent Females. Journal of Pediatric and Adolescent. Gynecology. 2006; 19(4): 2715. doi: 10.1016/j.jpag.2006.05.002. PMID: 16873031.

8) Emdadul HS, Rahman M, Istuko K, Mutahara M, Sakisaka K. The effect of school -based educational intervention of menstrual health:an intervention study among adolescent girls in Bangladesh. BMJ Open. 2014; 4(7): e004607. doi: 10.1136/bmjopen-2013-004607. PMID: 24993753, PMCID: PMC4091465.

9) Sapkota D, Sharma D, Budhathoki S, Khanal V, Pokharel H. Knowledge and practices regarding menstruation among school going adolescents of rural Nepal. Journal of Kathmandu Medical College. 2013; 2(5): 122.

10) Gómez-Sánchez P, Pardo- Mora Y, Hernández-Aguirre H, Jiménez-Robayo S, Pardo-Lugo JC . Menstruation in history. Invest Educ Enferm. 2012; 30(3): 371-7.

11) Burnet Institute SM, Water Aid Australia, Aliansi Rem aja Independen. Menstrual Hygiene Management in Indonesia. Understanding practices, determinants and impacts among adolescents' school girls. Final reports; 2015.

12) Heshmati H, Hazavehei S, Dehnadi A, Hasanzadeh A. Related Factors to Educational Behaviors of Health Volunteers about Cutaneous Leishmaniasis on the Basis of BASNEF Model in Yazd. Journal of Health and Hygiene. 2010; 6(1).

13) FSG. Menstrual Health in Ethiopia | Country Landscape Analysis. 2016: 15.

14) Selamawit T, Kuribachew M, Pasquina A, Rozalia M, CHemisto S, Lindiwe N. Towards a sustainable solution for school menstrual hygiene management: cases of Ethiopia, Uganda, South Sudan, Tanzania and Zimbabwe. Waterlines. 2015; 34(1): 92-102. doi: 10.3362/1756-3488.2015.009.

15) Abaszadeh M. Accuracy and stability in qualitative studies. Applied sociology. 2012; 23(1): 19-34.

16) Graneheim UH, Lundman B. Qualitative content analysis in nursing research: concepts, procedures and measures to achieve trustworthiness. Nurse Educ Today. 2004; 24(2): 105-12. doi: 10.1016/j.nedt.2003.10.001. PMID: 14769454.

17) House $S$, Mahon $T$, Cavill S. Menstrual hygiene matters: A resource for improving menstrual hygiene around the world. Reproductive Health Matters. 2013; 21(41): 257-9.

18) Tegegne TK, Sisay MM. Menstrual hygiene management and school absenteeism among female adolescent students in Northeast Ethiopia. BMC public health. 2014; 14: 1118. doi: 10.1186/1471-2458-14-1118.

19) Asia T, Talib L, Ghulam M, Shujaat A, Amara M, Muhammad H, et al. Iron Deficiency Anaemia in Reproductive Age Women Attending Obstetrics and Gynecology Outpatient of University Health Centre in Al-Ahsa, Saudi Arabia. African Journal Traditional Complementory Alternative Medicine. 2014; 11(2): 339-42. doi: 10.4314/ajtcam.v11i2.19.

20) (UNESCO)United nations educational Sacco. Puberty education \& menstrual hygiene management, and good policy and practice health education. Paris: The United Nations Educational, Scientific and Cultural Organization by place de Fontenot; 2014.

21) McMahon S, Winch P, Caruso B, Obure A, Ogutu E, Ochari I, et al. 'The girl with her period is the one to hang her head' Reflections on menstrual management among schoolgirls in rural Kenya. BMC Int Health Hum Rights. 2011; 11: 7. doi: 10.1186/1472-698X-11-7. PMID: 21679414, PMCID: PMC3129305.

22) Morgan C, Bowling M, Bartram J, Kayser GL. Water, sanitation, and hygiene in schools: Status and implications of low coverage in Ethiopia, Kenya, Mozambique, Rwanda, Uganda, and Zambia. Int J Hyg Environ Health. 2017; 220(6): 950-9. doi: 10.1016/j.ijheh.2017.03.015. PMID: 28539190.

23) Karon A, Cronin A, Cronk R, Hendrawan R. Improving water, sanitation, and hygiene in schools in Indonesia: A cross-sectional assessment on sustaining infrastructural and behavioral interventions. Int $\mathrm{J}$ Hyg Environ Health. 2017; 220(3): 539-50. doi: 10.1016/j.ijheh.2017.02.001. PMID: 28238610. 
24) Soltanahmadi Z, Borhani F, kohan M. The First Menstruation Experience among Student Girls. J Qual Res Health Sci. 2012; 1(2): 81-91.

25) Montgomery P, Ryus CR, Dolan CS, Dopson S, Scott LM. Sanitary Pad Interventions for Girls' Education in Ghana: A Pilot Study. PLoS One. 2012; 7(10): e48274. doi: 10.1371/journal.pone.0048274. PMID: 23118968, PMCID: PMC3485220.

26) Najafi F, Mozafari S, Mirzaee S. Assessment of 3rd Grade Junior School Girl Students' Knowledge and Attitude toward Puberty Age Sanitation. Journal of Guilan University of Medical Sciences. 2012; 21(81): 22-8.

27) Aghajani N, Dolat pour E. Study the educational role of television in the improvement of the traffic behavior of the citizens of Tehran. Culture Of Communication. 2012; 2(7): 1-33.

28) Afshary P, Mohammadi S, Koshteh S, Pajohideh SZ, Tabesh H. Survey on prevalence and causes of selfmedication in women referring to health centers in Ahwaz, in 2013. Iran South Med J. 2015; 18(5): 103444. doi: 10.7508/ismj.1394.05.011.

29) Ershadpour R, Zaremarzoni H, Kalani N. Review survey of the reasons of the prevalence of selfmedication among the people of Iran. Navid No . 2015; 18(60): 16-23. doi: 10.22038/nnj.2015.6324. 